\title{
sciendo
}

RESEARCH PAPERS FACULTY OF MATERIALS

SCIENCE AND TECHNOLOGY IN TRNAVA

SLOVAK UNIVERSITY OF TECHNOLOGY

IN BRATISLAVA

2020, Volume 28, Number 46

DOI 10.2478/rput-2020-0008

\section{IMPROVING PRODUCTS QUALITY APPLYING SIX SIGMA}

\author{
Martin MAREČEK-KOLIBISKÝ ${ }^{1}$, Marta KUČEROVÁ ${ }^{1}$ \\ ${ }^{1}$ SLOVAK UNIVERSITY OF TECHNOLOGY IN BRATISLAVA \\ FACULTY OF MATERIALS SCIENCE AND TECHNOLOGY IN TRNAVA \\ INSTITUTE OF INDUSTRIAL ENGINEERING AND MANAGEMENT \\ ULICA JÁNA BOTTU 2781/25, 91724 TRNAVA, SLOVAK REPUBLIC \\ e-mail: martin.marecek-kolibisky@stuba.sk, marta.kucerova@stuba.sk \\ Received 15 April 2020, accepted 11 May 2020, published 25 June 2020
}

\begin{abstract}
The contribution is aimed at improving the process of production of certain products by applying the Six Sigma methodology. It is a practical application of this methodology in an industrial company in solving a specific issue. Six Sigma uses the DMAIC logic cycle, which was also applied to the project. The aim of the project was to eliminate the process of calibrating parts after hardening, which were marked as nonconforming products. By applying the DMAIC logic cycle, improvements were made that shortened the production process and time to deliver production orders to the customer, reduce production costs, and retain a significant customer.
\end{abstract}

Key words

Six Sigma, DMAIC, quality, nonconforming products, calibration process, improving

\section{INTRODUCTION AND THEORETICAL BACKGROUND}

Companies need Quality Management to improve a spectrum around the companies' business (business processes, performance and competitiveness). Companies had begun to implement quality management systems because Quality Management had positive benefits for companies [12]. "This has led to the emergence of a number of process improvement related quality management methods or frameworks, such as Six Sigma, Total Quality Management (TQM), business process reengineering/management, and relevant standards" [11].

Six Sigma is one of the methods of industrial engineering. It is used in industrial enterprises to improve processes. Six Sigma uses many methods, techniques, and tools of industrial engineering, quality management, and statistical methods. Six Sigma is not only used in the production sphere, but can be applied in various companies, e.g. in improving administrative processes, banking, etc. Six Sigma is mostly used to solve such problems that cannot be solved more easily (so to speak with peasant mind). It is difficult to achieve the set target. Six Sigma 
projects can have different solution times, mostly lasting for 3 to 6 months, while demanding projects last longer [8].

Six Sigma serves to improve the quality of products and services, maximize productivity and profit. The basis is a perfect examination of customer expectations and requirements. Problem solving uses statistical methods and quality management tools to eliminate errors, quantify waste, and indicate steps for improvement $[14,6]$.

Six Sigma methodology was primarily progressing by Motorola in the 1980s and it has now branched out to many industry sectors. It targeted a difficult aim of 3.4 parts per million defects [13]. This value is very nearer to zero-defect manufacturing level. In order to achieve 3.4 DPMO of quality level, Six Sigma progresses through many stages by adopting several tools, techniques and approaches [16].

The demonstrable benefits and benefits of Six Sigma for the enterprise include: Increase of productivity, increase of market share, retained customer, reduced service production, reduced errors, changed business culture and design of new products and services [1].

The fact that implementation facilitates the achievement of continuous quality improvement without losing profitability is a unique feature of Six Sigma [15].

The basic principles of Six Sigma that distinguish them from other methods are [3]: Customer orientation, process orientation, employee orientation, management and improvement based on data information and knowledge, standard process improvement approach - DMAIC cycle, proactive management and Six Sigma support.

The Six Sigma central solution is a combination of a DMAIC-based approach that is tooloriented and it is structured. However, Six Sigma is more than an established analytical tool based on scientific statistical methods. From the outset, it has been a systematic and rigorous methodology for optimizing business processes with the goal to meet all critical, profit-oriented customer and business requirements [4].

The ability and strength of Six Sigma depend on the standard approach of the cycle and the basic DMAIC tool. Other tools and methods are used in its individual phases. The tools and methods used in Six Sigma are used to streamline processes and products. These quality management tools and methods have been used for many years [2].

Six Sigma has a fixed structure and method with a logical process called DMAIC for process improvement. This logical process is oriented in a cycle, because the individual phases are connected to each other and, with continuous improvement, this cycle is repeated. DMAIC is a valuable tool that helps managers and workers find lasting solutions to long-term or complex business problems. The basic framework works well in many situations, yet the use of DMAIC involves time and cost [5].

The paper deals with the improvement of the production process of certain parts by applying the standard logical cycle of DMAIC. The aim of the project was to eliminate the number of calibrated parts.

\section{MATERIALS AND METHODOLOGY OF EXPERIMENT}

The paper deals with the issue of increased number of nonconforming products and an increase in the process of calibrating parts after hardening. The resulting problem was solved by Six Sigma and the application of the DMAIC logic cycle. This procedure ensures logical arrangement of parts and results in proposed solutions and their implementation in the company.

\section{Define}

The Define phase describes the process to be improved. The process description also includes the scope (beginning and end of the process, inputs and outputs). In this phase, the goal is clearly defined [7]. 
Based on the requirements of the project sponsor, it was necessary to set up a solution team, identify the main problem, then define a key criterion from the perspective of the company and propose project objectives.

Initial situation: at the production department there was an increase in the need for calibration after quenching. More parts have been calibrated than in the past. There was a lack of calibration capacity and bottlenecks. Continuous production time increased, supplies dropped, customer exit threatened and calibration also increased price. At the production department, they were considering buying another calibrator, but it would be costly for the entire segment.

Objectives: Eliminate the need for calibration after hardening for given type dimensions.

Measured parameters: Number of hardened parts number of calibrated parts.

The aim of the project was to eliminate the need for calibration after hardening for selected types of dimensions. The objective is achieved by improving the processes that precede the calibration process after quenching. The problem concerned three types of Needle cages (Fig. 1) and their dimensions, where the outer diameter of the product was deformed or rounded. Type dimensions in the paper are referred to as Type 1, Type 2, and Type 4. Each type has different size parameters and each of the Needle cages are constructed from steel.
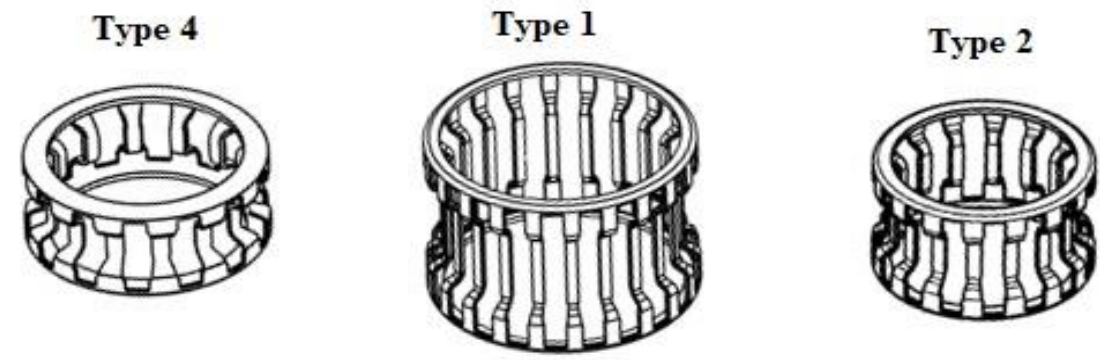

Figure 1 The different types of Needle cages (Internal company source)

By initially defining and observing the process, it has been found that even those products that do not need to be calibrated are calibrated and subsequently those that require calibration are not calibrated. The calibration process is chaotic. The following table (Table 1) shows the quantity of parts in production orders, the number of calibrated parts and the individual type dimensions.

Table 1 Number of calibrated parts in Production Orders (PO) (Own processing)

\begin{tabular}{|c|c|c|}
\hline Types of the products & Number calibrated parts & Number of calibrated parts in PO \\
\hline Type 1 & $\mathbf{7 2 9 1 6} \mathbf{~ p c}$ & $108636 \mathrm{pc}$ \\
\hline Type 2 & $\mathbf{1 2 5} \mathbf{7 4 1} \mathbf{~ p c}$ & $146992 \mathrm{pc}$ \\
\hline Type 4 & $\mathbf{7 5 4 4 3} \mathbf{~ p c}$ & $75443 \mathrm{pc}$ \\
\hline
\end{tabular}

The dimensions must meet the quality requirements, the quality of the products in question must not be impaired by optimization and subsequent reduction of calibration. The cost of products or production orders must not be increased by optimization; optimization of calibration should result in cost reductions for the segment and for the entire company. Delivery reliability will be improved by this optimization of calibration and deliveries and orders themselves should be processed more quickly. Optimization and reduction of calibrated parts will ensure a smoother flow of supplies, saving calibration costs, increasing calibration capacity, resulting in the elimination of bottlenecks. The general procedure for the production of parts and the technological parameters of these parts were determined by the customer himself. The use of the material and the subsequent production technology cause the material 
to shrink or the shape imperfections of the semi-finished products arise, so it is necessary to calibrate these parts.

The production department wanted to invest in the purchase of a new calibration machine, but after financial evaluation, this proposal was rejected. The cost of investing in a calibrator is around $130,000 €$ and additional costs would be to operate the machine.

The parts are calibrated before calibration, the inspection is performed by measuring the outside diameter using a PRG gauge (ring and mandrel inspection) and a digital outside diameter gauge. Both of these part inspections have a high impact on the outside diameter of a given dimension. In the case of negligent checks with PRG, deformation of the external dimensions of the cages may occur, and conversely, in the case of digital scale inspections, measurement errors or incorrect insertion of the cages into the instrument and consequent measurement inaccuracy may occur.

Using the SIPOC tool (Fig. 2), the process of manufacturing the dimensional dimensions was mapped. The beginning and end of the process was determined. Processes that are within the scope of the project and processes that are outside the scope of the project, processes that do not affect the deformation of parts, have also been identified.

Within the scope of the process, there are following parts in process: emery, grinding, sandblasting, tumbling, hardening, calibrating and the monitored types (Type 1, Type 2 and Type 4).

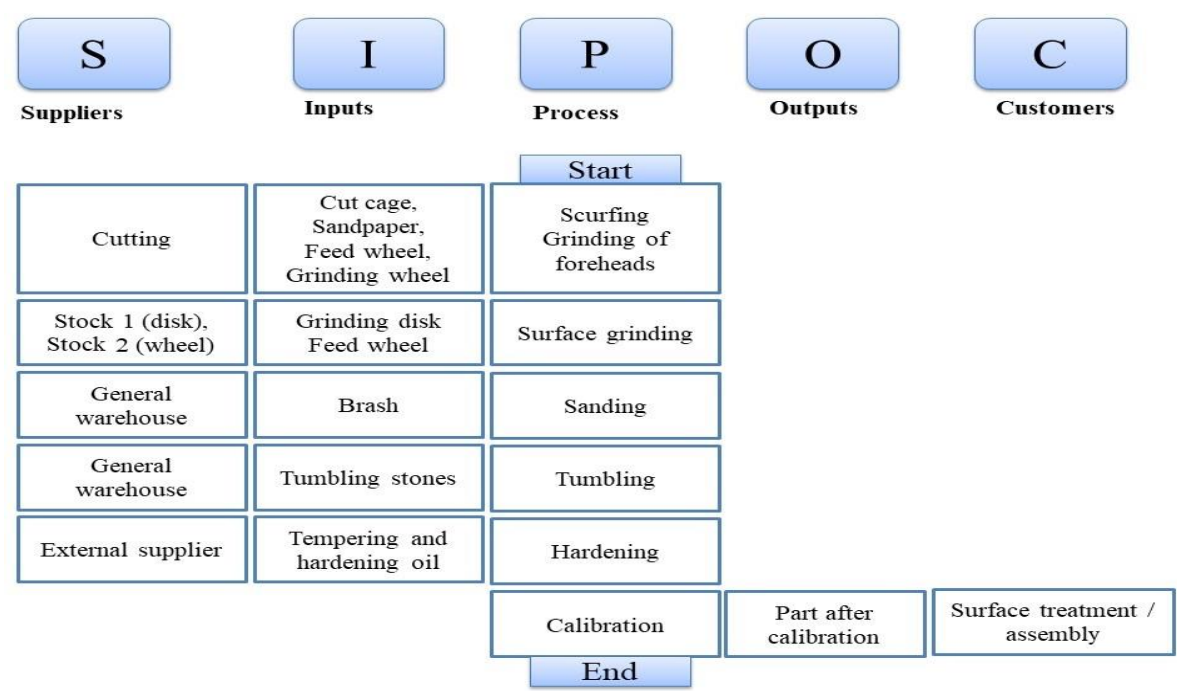

Figure 2 Diagram of SIPOC process of production of dimensional dimensions (Own processing)

\section{Measure}

The phase provides collection and evaluation of information on the current state, this data is to help find the cause of the problem, the work team discovers and understands how the process actually works, collecting data from different sources [8].

In the Measure phase, the capability of the measuring system was checked. There were two PRG measuring devices and a digital measuring device to measure the external diameter of the parts.

The PRG measuring method was as follows: 30 parts were produced, of which five were $\mathrm{NiO}$ (nonconforming) parts. The parts were measured on a digital scale and marked and spilled into a crate. Quality control operators did not have information on which asset is iO (compliant) or $\mathrm{NiO}$ (non-compliant). Two quality operators measured all parts twice. After each measurement, the part designation changed. One quality control operator identified the products in the right way as $\mathrm{iO}$ and $\mathrm{NiO}$. The other operator made one mistake in one inspection, where iO part was classified as $\mathrm{NiO}$ part. After checking all parts, the operators performed this check 
once more to verify the stability of the process. Subsequently, the measured data were processed by the Minitab program. By examining the quality and reliability of the output data, it was found that measuring the outside diameter with PRG is an acceptable process. The standard was found to be $98.3 \%$ indicating that the measurement process is eligible.

Digital measuring method: parts were measured on the scale, the results were processed by Minitab. Individual measured features had different tolerance limits. Minitab reports evaluate all meter capability statistics, meter tolerance, maximum and minimum values, variance, meter capability coefficients. The resulting values for the gauge indexes of the gauge were as follows: for a $10 \mathrm{~mm}$ circle, the gauge index of gauge $c_{\mathrm{g}}=2.04$ and the critical gauge index of gauge $c_{\mathrm{gk}}$ $=1.47$; the measuring system is eligible. For other measured features, the capability index values were at capability intervals, i. $c_{g}, c_{g k} ; 1.33$, respectively. $c_{g}, c_{g k}>1$ and $c_{g}>c_{g k}$.

Based on the calculated capability indices, the measurement system is eligible for all measured characteristics.

\section{Analyse}

The purpose of the analysis is to identify the key cause of the problem, which has a significant impact on the occurrence of the problem. Qualitative and quantitative analyses in the process were also performed [9].

The analysis phase is based on the obtained process information with the Define and Measure phases. The main starting point for the analysis phase was the creation of the Ishikawa diagram from the known information. During the analysis phase, the research team compiled an extensive Ishikawa diagram to determine the causes of the increased number of calibrated parts. Selected were the areas for which causes were sought and which had a potential impact on the problem. The main areas were Machine, Human, Material, Method and Scale. The problem we set out in the Ishikawa diagram as the question: "Why do we calibrate more than $20 \%$ of the total annual production?"

\begin{tabular}{|c|c|c|}
\hline Rankings & Title & Points \\
\hline 1 & Enter the operation into hardening & 30 \\
\hline 2 & Unstable hardening process & 26 \\
\hline 3 & Unsuitable hardening oil & 13 \\
\hline 4 & Inaccuracy of previous operations & 12 \\
\hline 5 & Unsuitable type of hardening & 11 \\
\hline 6 & Insufficient number of measurements & 8 \\
\hline 7 & Interoperational control & 7 \\
\hline
\end{tabular}

Team members suggested the reasons they believe were posing a problem with the calibration process. Following the brainstorming, the causes were categorized into individual areas. Teams suggested 20 causes. These causes were potential drivers of the calibration process problem. For each cause, using "5 times why?" Search for sub-causes that contribute to solution of the overall cause. The importance of the causes was expressed by team members by assigning points. The order of causes was determined by the score. The most important causes were identified - the TOP 7 causes for the subsequent verification of the impact on the calibration process (Enter the operation into hardening, Unstable hardening process, Unsuitable hardening oil, Inaccuracy of previous operations, Unsuitable type of hardening, Insufficient number of measurements, and Interoperational control). 


\section{ATTAINED RESULTS AND DISCUSSION}

\section{Improve}

The basis for the improve phase is to eliminate the real causes of the problem. New process parameters and process optimization are set. This is done to increase customer satisfaction, external or internal. The aim of the phase is to find, verify and implement solutions to solve the problem [6].

In the Improve phase, it was proposed to change and modify drawings for each type, i.e. a new production order technology for each type. The Improve phase indicates the analysis phase where the top seven causes why the problem may have arisen were tested and verified. It was found the in causes that enter the operation into hardening and Inaccuracy of previous operations shortcomings in grinding to a certain tolerance were found. And for this reason, corrective measures were designed and implemented.

The analysis showed that deformation of the parts did not occur if the parts are manufactured to the lower tolerance limit. On the basis of this finding, proposed was the adjustment, or a change of drawing parameters for the Type 1 and Type 2 dimensions, and also a change of the mould parameters for pressing and a change of hardening type for the Type 4 dimension was proposed.

\section{Change grinding parameters}

The basis for this change of data was inaccuracy of previous operations (window cut). After measuring the dimensions after each operation and on the basis of the process data, it was found that, for the Type 1, the measured values were very close to the upper tolerance limit for some parts, or above the upper tolerance limit for other parts. Based on this fact, the technologist in the segment proposed adjusting the dimensions for grinding at the Type 1 thyroid dimension. The nominal dimension for grinding was changed from $41.77 \pm 0.03 \mathrm{~mm}$ to $41.74 \pm 0.03 \mathrm{~mm}$. By changing the grinding dimensions, the values shifted to the centre of the tolerance field. As a result of this change, the parts did not need to be calibrated, and the dimensions of the parts produced were within tolerance. The changes were consulted with customers, and then tested and approved by the customer, provided that there were no final changes in the product parameters. The final products met the customer requirements.

\section{Modification of the mould for pressing}

Analysing the dimensions of the parts and measuring the parts was also performed for the Type 2 dimension. For this product, which was one of the two most numerous parts for the calibration process, the mould was modified. This part is not ground; there is another kind of operations specified in the technological process, or a production process, which is determined by the customer. For this reason, this type of dimension had to be changed at the very beginning of the process. The mould was adjusted only for the outer diameter, other dimensions of the mould were unchanged. The diameter was changed from the original dimension $\phi 28.8 \pm 0.025$ $\mathrm{mm}$ to a value of $\phi 28.75 \pm 0.025 \mathrm{~mm}$. The adjustment of the mould dimensions was sufficient to prevent the Type 2 dimension from being calibrated and to retain all design features. The changes were consulted with customers, and then tested and approved by the customer, provided that there were no final changes in the product parameters. The final products met the customer requirements.

At the beginning of the project, the level of calibration was $78 \%$ of parts for the Type 1 and Type 2 dimensions, specifically $77.7 \%$ of parts had to be calibrated. After implementation of the proposed solutions, the quantity of calibrated parts was $10.7 \%$. The level of calibrated parts before and after the implementation of the measures is shown graphically in (Fig. 3).

In the industrial plant in question, $20 \%$ of parts from the entire production order are allowed to be calibrated. After implementing the solutions, the amount of parts to calibrate for five production orders was less than the threshold. 
Within the scope of the project, the dimensions were changed in the design documentation for the grinding operation and in the production of the mould for pressing. No costs were incurred to change these parameters. After the implementation of the proposals, the annual cost savings of $21,400 €$ were expressed, and it was also not necessary to purchase a new calibrator worth $120,000 €$.

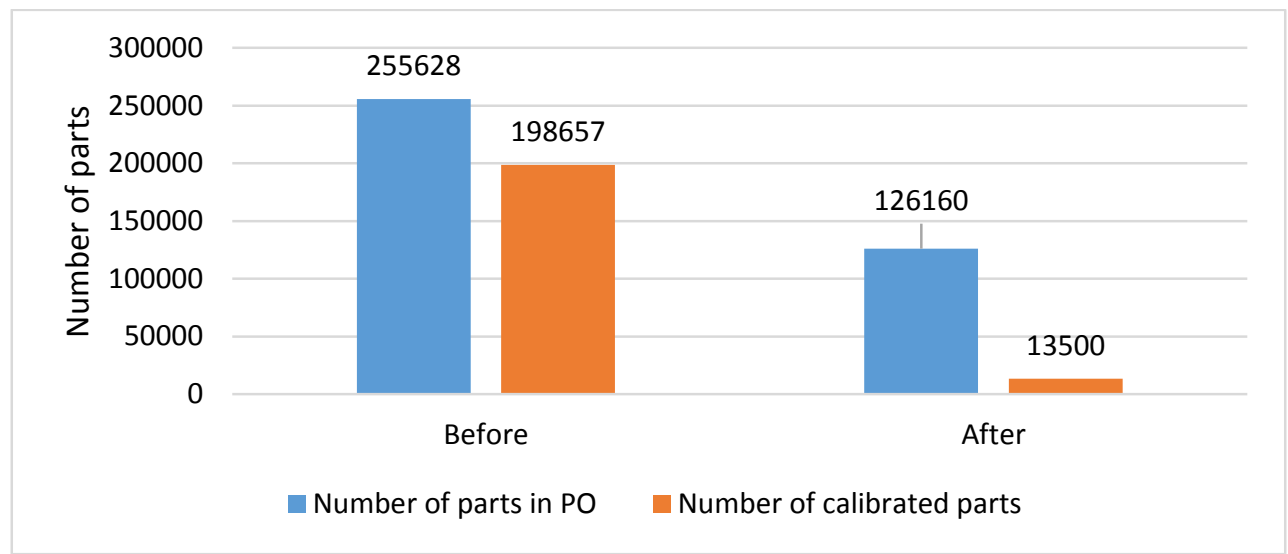

Figure 3 Number of calibrated parts before or after project implementation (Own processing)

\section{Control}

If the achievable improvement is truly effective and beneficial, it is necessary to maintain and protect this solution [10].

The corrective measures applied for the Type 1 and Type 2 dimensions were effective and, as mentioned above, represent visible improvements compared to the baseline. Based on this improvement trend, it is necessary to regularly monitor the parts production process and the number of calibrated parts should not exceed $20 \%$ of parts per two production orders. This will ensure that the production process is continuous at the production department, thus eliminating the need for a calibration process and avoiding bottlenecks.

As part of the project, regular inspections of two production orders for 3 months were proposed. If the obtained / measured values of the control parameters are satisfactory and the limit of $20 \%$ of the parts to be calibrated is not exceeded, a moderate control can be performed. The employees have to carry out checks on production orders. In this method of control, the parameters will be checked after the pressing, grinding and hardening processes. If the three parameters are at the lower tolerance limit, there is no need to calibrate the parts. The values of the measured parameters will be collected by the given production department (technologist, designer) in cooperation with the production operators who carry out control measurements after these operations. If the condition and results worsen, it will be necessary to quickly and accurately assess where the problem occurred.

\section{CONCLUSION}

In the paper, Six Sigma was presented as a practical example and applied to a project in a particular industrial company. The project focused on the problem of the great need for the calibration process after hardening. Using Six Sigma, improvements have been made to speed up the manufacturing process of parts, enable faster handover of production orders to the customer, help save money for the production department, and ensure the retention of a major customer. Six Sigma is not just a methodology, it is also a philosophy that companies use to bring obvious benefits. Six Sigma as such can be used for various projects, depending on the duration. Shorter as well as longer projects can be solved. It can be used both in production processes and in processes in logistics and administration; the banks also use Six Sigma in their 
processes. Six Sigma uses a large number of tools, methods and techniques. The abovementioned tools and methods were used in the above-mentioned project, since they brought the required contribution into solving this project.

However, the improvement process does not end with implemented measures and implementation of changes in design documentation. It is necessary to constantly monitor the production process of the products, monitor key parameters as well as analyse and evaluate the data obtained.

\section{References}

[1] PYZDEK, T., KELLER, P. 2013. The handbook for quality management. 2nd ed. The McGrawHill Companies, 2013. 497 p. ISBN 978-0-07-179924-9

[2] www.ipaslovakia.sk, DMAIC - Model riadenia Six Sigma projektu (A model of the Six Sigma project management). [online]. [Accessed 01-2020]. Available at: https://www.ipaslovakia.sk/sk/ipa-slovnik/dmaic-model-riadenia-six-sigmaprojektu.

[3] HECKL, D., MOORMANN, J., ROSEMANN, M. 2010. Uptake and success factors of Six Sigma in the financial services industry. Bus Process Manag J. 16(3), pp. 436-472.

[4] MERAN, R. 2013. Six Sigma +Lean Toolset. 2nd ed. Berlin: Springer. 2013. 400 p. ISBN 978-3642-35882-1

[5] MILLER, I. 2016. Kapesní přiručka Six Sigma. 3rd ed. Prague: INTERQUALITY. 2016. 147 p. ISBN 978-80-902770-4-5

[6] SCHROEDER, G. 2008. Six Sigma: Definition and underlying theory. Journal of Operations Management, 26, 536-554 p.

[7] BRUE, G. 2005. Six Sigma for Managers. McGraw-Hill. 2005. 64 p. ISBN 978-0-071-45548-0

[8] McADAM, R., ANTONY, J., KUMAR, M., HAZLETT, SA. 2014. Absorbing new knowledge in small and medium-sized enterprises: A multiple case analysis of Six Sigma. International small business journal-researching entrepreneurship, 32(1), 81-109.

[9] THOMSETT M.C. 2005. Getting Started in Six Sigma. New Jersey: John Wiley and Sons, 222 p. ISBN 0-471-66811-7

[10] SUBIRÁ CONCEICAO, R. et al. 2019. Lean Six Sigma: Implementation of improvements to the industrial cost management. Independent Journal of Management and production, 10(6), 2023 2045.

[11] GRAAFMANS, T. et al. 2019. Process Mining for Six Sigma. A Guideline and tool Support. Research paper. [online]. [Accessed: 04-2020]. Available at: https://link.springer.com/content/pdf/10.1007/s12599-020-00649-w.pdf

[12] TJAHJONO, B., BALL, P., VITANOV, V.I. et al. 2010. Six sigma: a literature review. International Journal Lean Six Sigma. 1(3), 216-233.

[13] SONI, S., MOHAN, R., BAJPAI, L., KATARE, S.K. 2013. Reduction of welding defects using Six Sigma techniques. International Journal of Mechanical Engineering and Robotics Research, 2(3), 404-412.

[14] KUMAR, A., KUMAR BAGRI, S. 2013. Improving the Productivity of Lever Combination Switch using Continuous Improvement Process. International Journal of Soft Computing and Engineering (IJSCE), 3 (2), pp. 174-177. ISSN 2231-2307.

[15] VINOD, M. et al. 2015. Six Sigma through Poke-Yoke: a navigation through literature arena, International Journal adv Manufacturing Technology, 81, pp. 315 - 327.

[16] SAGHAEI, A., NAJAFI, H., MIGHI, A., MOSANNA, Z. 2014. Mathematical modelling to improve rolled throughput yield in a supply chain. Prod Plan Control, 25(5), pp. 414-424.

\section{ORCID}

Martin Mareček-Kolibiský 0000-0003-2000-1206

Marta Kučerová 0000-0002-0392-5805 